\title{
Critical appraisal of nilotinib in frontline treatment of chronic myeloid leukemia
}

\author{
This article was published in the following Dove Press journal: \\ Cancer Management and Research \\ 9 March 201I \\ Number of times this article has been viewed
}

\author{
David L DeRemer ${ }^{1,2}$ \\ Katerina Katsanevas ${ }^{1,2}$ \\ Celalettin Ustun ${ }^{3}$ \\ 'Department of Clinical and \\ Administrative Pharmacy, College \\ of Pharmacy, University of Georgia, \\ Augusta, GA, USA; ${ }^{2}$ Medical College \\ of Georgia Health Inc, Augusta, \\ GA, USA; ${ }^{3}$ Department of Medicine, \\ Section of Hematology/Oncology, \\ University of Minnesota, Minneapolis, \\ MN, USA
}

\begin{abstract}
The development of imatinib has revolutionized the treatment of chronic myeloid leukemia. Follow-up analysis of IRIS trial participants continues to demonstrate durable responses for imatinib at $400 \mathrm{mg} /$ day. However, 10\%-15\% of patients with chronic myeloid leukemia will become imatinib-resistant or intolerant of adverse events. Phase II studies have shown that most of these patients will respond to second-generation tyrosine kinase inhibitors, such as nilotinib, dasatinib, and bosutinib. Both nilotinib and dasatinib have recently demonstrated clinical efficacy as frontline therapy in Phase III studies. In the ENESTnd trial, nilotinib $600-800 \mathrm{mg} /$ day produced significantly higher major molecular rates and complete cytogenetic response rates in comparison with imatinib at 12 months. Recently, 18-month follow-up analysis of this trial continues to demonstrate superiority for nilotinib. It is unknown whether this will ultimately translate into improved long-term outcomes, such as event-free survival or overall survival. Nilotinib continues to be generally well tolerated and tends to produce less Grade 3/4 toxicity in frontline therapy when compared with its use following imatinib failure. With three tyrosine kinase inhibitors for potential frontline therapy and an active drug discovery pipeline, treatment for chronic myeloid leukemia is still subject to change with time as clinical algorithms continue to evolve.
\end{abstract}

Keywords: nilotinib, frontline therapy, chronic myeloid leukemia, adverse events

\section{Introduction}

Chronic myeloid leukemia (CML) is a chronic myeloproliferative disorder that represents approximately $15 \%$ of all adult leukemias, with an estimated 4870 new cases in the US in 2010. ${ }^{1}$ The treatment of this disease has dramatically improved with the advent of targeted oral tyrosine kinase inhibitors (TKIs). Prior to the Phase III IRIS (International Randomized Interferon- $\alpha$ and STI-571) study, the standard of care was cytarabine and interferon- $\alpha$ in those patients who were unable to undergo allogeneic hematopoietic stem cell transplantation. Imatinib (STI-571, Gleevec ${ }^{\circledR}$; Novartis, Basel, Switzerland) demonstrated superiority in response rates and overall survival when compared with cytarabine and inferferon- $\alpha .^{2}$ Several follow-up analyses of IRIS study participants have continued to confirm the efficacy and safety of imatinib. ${ }^{3-5}$ However, some patients will develop imatinib resistance or intolerance to therapy. Imatinib intolerance is a significant clinical issue which leads to dose reduction or discontinuation. Adverse events associated with imatinib intolerance include myelosuppression, arthalgia/myalgia, fatigue, rash, and gastrointestinal symptoms. A 4-year analysis from the HealthCore Managed Care database revealed that, among 156 patients
Correspondence: David DeRemer University of Georgia College of Pharmacy, Medical College of Georgia, II 20 I 5th Street HMI 204, Augusta, GA 30912, USA

Email dderemer@mcg.edu 
receiving imatinib $400 \mathrm{mg} /$ day, $21 \%$ required a dose reduction to $100 \mathrm{mg} /$ day. The most common reasons for dose reduction were neutropenia, anemia, and nausea/ vomiting. ${ }^{6}$ In patients who develop resistance, higher doses of imatinib (600-800 mg/day) have been attempted. ${ }^{7}$ These patients are particularly subject to imatinib intolerance. Patients who received imatinib $600 \mathrm{mg} /$ day and $800 \mathrm{mg} /$ day required dose reductions of $59 \%$ and $67 \%$, respectively, most commonly for myelosuppression. The development of second-generation TKIs (dasatinib, nilotinib, bosutinib) has provided new options for CML patients, specifically those patients who are intolerant of or resistant to imatinib.

Dasatinib (BMS-354825, Sprycel $^{\circledR}$; Bristol-Myers Squibb, New York, NY) received accelerated approval in June 2006 for the treatment of patients with chronic phase, accelerated phase, or blast crisis CML who were imatinib-resistant and/or imatinib-intolerant. In October 2007, nilotinib (AMN107, Tasigna $^{\circledR}$; Novartis) was also granted accelerated approval for patients with chronic phase or accelerated phase CML deemed imatinib-resistant and/or imatinib-intolerant. Bosutinib (SKI-606) has not received US Food and Drug Administration (FDA) approval to date.

All three second-generation TKIs have demonstrated clinical benefit in multiple Phase II studies ${ }^{8-14}$ in patients with resistance and/or intolerance to imatinib. In June 2010, data were published for dasatinib and nilotinib in the frontline therapy setting for patients with chronic phase CML. Since this time, the FDA has granted approval for both dasatinib and nilotinib in newly diagnosed patients. The aim of this review is to examine the role of nilotinib in frontline therapy for CML. Specifically, this paper compares TKI response rates in frontline therapy, evaluates the adverse event profiles associated with these agents, and discusses specific TKIs according to their BCR-ABL mutation status.

\section{Pharmacology}

CML results from reciprocal translocation between chromosomes 9 and 22, which results in the Philadelphia chromosome. This event adds a 3 ' segment of the Abelson ( $A B L$ ) gene from chromosome $9 \mathrm{q} 34$ to the $5^{\prime}$ part of the $B C R$ gene on chromosome 22q11, creating a hybrid BCR-ABL gene. ${ }^{15}$ The BCR$\mathrm{ABL}$ transcript is also found in approximately $25 \%$ of patients with B cell acute lymphoblastic leukemia. ${ }^{16}$ The disruption of the $\mathrm{ABL}$ protein results in a constitutively active tyrosine kinase which promotes proliferation, resistance to apoptosis, and alters cell adhesion. The development of small molecule TKIs that would occupy the adenosine triphosphate-binding site in the ABL kinase domain was pursued. By creating compounds that would reside in the adenosine triphosphate-binding pocket, this would prevent the phosphorylation of numerous substrates and trap the $\mathrm{ABL}$ kinase in the inactive conformation. This was first achieved by the development of the phenylaminopyrimidine derivatives that were synthesized and screened. One of the compounds (CGP 57148) had activity against platelet-derived growth factor, c-KIT, and BCR-ABL; later this compound became known as STI571, or imatinib. ${ }^{17,18}$ Although this discovery has dramatically improved the treatment of CML, the emergence of imatinib resistance has presented therapeutic challenges.

Like imatinib, nilotinib binds to the inactive conformation of the ABL tyrosine kinase. ${ }^{19}$ However, crystallographic studies have revealed an improved topological fit for the ABL protein. ${ }^{20}$ This is due to the design of more potent compounds that incorporate alternative binding groups. Altering the structure of imatinib, which participates in hydrogen bonding at Ile 360 and His361, nilotinib is designed to have more affinity for the kinase domain of ABL protein. ${ }^{21}$ Nilotinib is at least 30 times more potent than imatinib in cell lines expressing BCR-ABL. $\mathrm{IC}_{50}$ values which inhibit the autophosphorylation of various kinases are as follows: BCR-ABL (20-60 nM), platelet-derived growth factor (71 nM), and c-KIT $(200 \mathrm{nM}) .{ }^{20}$ Unlike other secondgeneration TKIs (dasatinib and bosutinib), nilotinib has minimal effects on Src family kinases $\left(\mathrm{IC}_{50}\right.$ values: c-Src, $4600 \pm 520 \mathrm{nM}$; Lyn, $2700 \pm 460 \mathrm{nM}$; Hck, $7500 \pm 830 \mathrm{nM}$ ). ${ }^{21,22}$ Src family kinases are a family of nine nonreceptor tyrosine kinases that play a role in cellular adhesion, angiogenesis, growth, and survival. Inhibition of Src family kinases is an attractive target in anticancer therapeutics, particularly in CML, because Src family kinases are able to activate BCR-ABL, and Hck and Lyn can become BCR-ABLindependent. ${ }^{23}$ Overexpression or activation of Hck and Lyn can occur in CML progression. ${ }^{24}$ Increased expression of Lyn kinase has been associated with nilotinib resistance in vitro. ${ }^{25}$ This lack of Src family kinase inhibition by nilotinib suggests that dasatinib should be favored as an initial CML treatment option. However, because Lyn is an important modulator of erythropoiesis and Hck is involved in the survival of myeloid cells and B lymphocytes, it has been proposed that nilotinib may have a more favorable adverse event profile with regard to myelosuppression. ${ }^{26-28}$ In fact, this has been demonstrated in clinical trial data where patients with chronic phase or accelerated phase CML who have 
received dasatinib have increased rates of Grade 3/4 adverse hematologic events. ${ }^{29,30}$

\section{Monitoring therapy}

The goals of current CML treatment are to reduce or eradicate the Philadelphia chromosome and BCR-ABL gene expression, to minimize adverse events for patients, and to improve event-free survival, progression-free survival, and overall survival. Oral TKI-based therapies are assessed for their ability to induce a complete hematologic response, complete cytogenetic remission, and major molecular remission ${ }^{31}$ (see Table 1 for definitions). A complete hematologic response is a normalization of peripheral blood counts with the absence of blasts and promyelocytes in peripheral blood. ${ }^{31}$ It is recommended that patients achieve a complete hematologic response within 3 months of initiating an oral TKI. ${ }^{31}$ Cytogenetics is the most commonly used technique to assess response to therapy. Conventional metaphase cytogenetic testing analyzes Philadelphia chromosome-positive bone marrow cells in a sample of $\geq 20$ cells. ${ }^{32}$ Definitions for cytogenetic response are as follows: none, with $>95 \%$ Philadelphia metaphases; minimal, 66\%-95\% Philadelphia metaphases; minor, 36\%-65\% Philadelphia metaphases; partial, $1 \%-35 \%$ Philadelphia metaphases; and complete cytogenetic remission, no Philadelphia metaphases. If conventional cytogenetics is performed and no analyzable metaphases are identified, fluorescent in situ hybridization can be utilized with peripheral blood samples or bone marrow aspirates. ${ }^{33}$ Fluorescent in situ hybridization assesses cytogenetic response in interphase cells and has a false positive rate of

Table I European LeukemiaNet (ELN) definitions of response ${ }^{31}$

Complete Hematologic Response (CHR)

WBC $<10 \times 10^{9} / \mathrm{L}$

Platelets $<450 \times 10^{9} / \mathrm{L}$

Basophils $<5 \%$

No myelocytes, promyelocytes, myeloblasts in differential

Nonpalpable spleen

Cytogenetic Response (CR)

Complete (CCyR) - 0\% Ph-positive metaphases

Partial (PCyR) - 1\%-35\% Ph-positive metaphases

Minor ( $\mathrm{mCgR})-36 \%-65 \%$ Ph-positive metaphases

Minimal (minCgR) - 66\%-95\% Ph-positive metaphases

Molecular Response (MR)

Complete (CMR) - BCR-ABL transcript is nonquantifiable by RT-PCR ** Major (MMR) - Ratio of the BCR-ABL:ABL $\leq 0.1 \%$ on international scale Reprinted with permission. ( 2008 American Society of Clinical Oncology. All rights reserved.

Note: **Must be confirmed in at least 2 sequential samples.

Abbreviations: WBC, white blood cell; BCR-ABL, breakpoint cluster region-abelson murine leukemia viral protooncogene.
$1 \%-10 \% .{ }^{1,32,34}$ Hypermetaphase fluorescent in situ hybridization provides greater sensitivity and can analyze 500 metaphases within an hour. ${ }^{35}$ Clinicians should use fluorescent in situ hybridization results with prudence; achievement of a complete cytogenetic remission cannot be confirmed by this method once Philadelphia levels are $<5 \%-10 \%{ }^{1,32}$

The most sensitive assay for assessing molecular response is the quantitative reverse-transcriptase polymerase chain reaction. This assay measures $\mathrm{BCR}-\mathrm{ABL}$ transcripts, and can be used for both peripheral blood and bone marrow samples. Results are expressed as log reductions; this is derived from 30 patients with untreated chronic phase CML who received imatinib in the original IRIS trial. ${ }^{36}$ In these patients, a $>3-\log$ reduction of $\mathrm{BCR}-\mathrm{ABL}$ transcripts were noted and resulted in a lack of disease progression. A major molecular remission is defined as a $\geq 3-\log$ reduction in $\mathrm{BCR}-\mathrm{ABL}$ transcripts or $\mathrm{BCR}-\mathrm{ABL} / \mathrm{ABL}$ ratio reduced to $\leq 0.1 \%$ on an international scale. ${ }^{31,36}$ Because the original 30 patient samples are no longer available for commercial standardization, collaboration between institutions has been essential in establishing a standard quantification of this process. ${ }^{37}$ The creation of international standardization led to a conversion factor which has allowed multiple academic institutions and private laboratories to improve their accuracy and reproducibility of BCR-ABL testing. ${ }^{37-39} \mathrm{~A}$ quantitative reverse-transcriptase polymerase chain reaction should be performed every 3 months until a major molecular remission has been confirmed, and thereafter at least every 6 months. Currently, European Leukemia Net recommendations require obtaining a complete cytogenetic remission at 12 months and a major molecular remission at 18 months. ${ }^{31}$ As time increases without achieving a complete cytogenetic remission, the probability of obtaining this diminishes and the risk of progression increases. ${ }^{40}$ Physicians are encouraged to be vigilant in pursuit of therapeutic goals.

With the addition of second-generation TKIs to frontline therapy, the use of the terms "event-free survival" and "progression-free survival" to define particular agents is under some scrutiny due to a lack of standardization. Differing definitions exist depending on the study and institution. In the IRIS trial, event-free survival was defined as occurrence of any of the following: death from any cause; progression to advanced accelerated phase or blast phase CML, loss of complete hematologic response or major cytogenetic response, or an increasing white blood cell count $\left(>20 \times 10^{9} / \mathrm{L}\right),{ }^{5}$ whereas event-free survival at the MD Anderson Cancer Center is coded as event equals progression to accelerated phase/blast phase in addition to loss of major 
cytogenetic response, loss of complete hematologic response, patient off TKI for toxicity, and death from any cause on or off therapy. ${ }^{41}$ For nilotinib in the ENESTnd (Evaluating Nilotinib Efficacy and Safety in Clinical Trials-Newly Diagnosed) study, progression was defined as advancing to accelerated phase/blast phase on TKI therapy, in addition to CML-related death on therapy. ${ }^{42}$ As more patients receive second-generation TKIs in frontline therapy, it is necessary to standardize these commonly used terms to make better long-term comparisons with imatinib.

\section{Nilotinib in frontline CML treatment}

The study by Rosti et al ${ }^{43}$ evaluated nilotinib $400 \mathrm{mg}$ twice daily in chronic phase CML patients who were diagnosed up to 6 months before study entry. Patients could have received hydroxyurea or anagrelide prior to study enrollment. This multicenter single-arm study did not permit dose escalation, but patients could receive dose modifications based upon hematologic and nonhematologic adverse events. Bone marrow aspirates were performed at months 3, 6, and 12 for cytogenetic analysis. Quantitative BCR-ABL transcript analysis was evaluated in peripheral blood samples collected at months 1, 2, 3, 6, 9, and 12. A major molecular remission was defined as a $\mathrm{BCR}-\mathrm{ABL}$ : $\mathrm{ABL}$ ratio reduction of at least threefold. Achieving a major molecular remission has been associated with durable remission rates, and is a goal of current oral TKI-based CML therapy. ${ }^{1,36}$ A failure to obtain a major molecular remission within 18 months of treatment indicates a suboptimal response. ${ }^{44}$

The primary endpoint for this study was a complete cytogenetic remission at 1 year. Secondary endpoints included complete and partial cytogenetic responses at 6 months, major molecular remission at 1 year, development of BCR-ABL mutations during treatment, and safety and tolerability of nilotinib $400 \mathrm{mg}$ twice daily. Seventy-three patients were enrolled in this Phase II study. A complete hematologic response was reported in $100 \%, 98 \%$, and $97 \%$ at months 3, 6, and 12 , respectively, in all patients. Notable complete cytogenetic remission was also described, ie, $78 \%$, $96 \%$, and $96 \%$ at months 3, 6, and 12 . At the time of publication, only one patient who had achieved a complete cytogenetic remission at 3 months relapsed to blast crisis with a T315I BCR-ABL mutation at 6 months. ${ }^{43}$ Updated information from this trial was presented at the 2009 American Society of Hematology meeting. Seventy-four percent of study participants received a median daily nilotinib dose of
600-800 mg. However, during the first year of the study, treatment was interrupted in 38 patients ( $52 \%$ overall, 86 interruptions) at least once. The median cumulative duration of nilotinib interruption was 19 (range 3-169) days per patient. Adverse events and tolerability of nilotinib will be discussed later in this review. With a median follow-up of 15 (range 12-24) months, complete cytogenetic remission at 12 months was $96 \%$, and major molecular remission was $85 \% .{ }^{45}$

Investigators at MD Anderson Cancer Center also evaluated nilotinib as frontline treatment in a single-arm Phase II study. Patients received nilotinib $400 \mathrm{mg}$ twice daily, administered on an empty stomach. To be eligible for study enrollment, patients were required to have had a diagnosis of CML during the 6 months before the study, have had no treatment other than hydroxyurea or a 1-month maximum of imatinib $400 \mathrm{mg}$ daily, be aged $\geq 18$ years, have performance status of $0-2$, and normal organ function. The primary objective of this study was to evaluate the major molecular remission rate at 12 months compared with historical controls (from the IRIS study) who had received imatinib 400-800 mg daily. Other endpoints evaluated were overall survival, event-free survival, and transformation-free survival. $^{46}$

Sixty-one patients were evaluated in this analysis. Twelve patients $(20 \%)$ had received a standard dose of imatinib for a median 22 (range 2-28) days prior to initiating nilotinib. At the time of publication, median follow-up was 17 (range 1-43) months. Fifty-one patients had been enrolled on study for a minimum of 3 months, and thus were evaluable for molecular and cytogenetic response. The median time to major molecular remission was 3 months (range 3-18) months and was achieved by $39(76 \%)$ of patients at this time point. At 12 months, $81 \%$ of patients had achieved a major molecular remission. ${ }^{46}$ These molecular responses favored nilotinib over imatinib based on historical controls. The standard dose of imatinib $400 \mathrm{mg}$ daily produced a major molecular remission in $46 \%$ of patients at 12 months, whereas imatinib $800 \mathrm{mg}$ daily led to a major molecular remission in $54 \%$ of patients. ${ }^{47}$ Cytogenetic responses also favored patients who had received nilotinib therapy. Early and durable cytogenetic responses have been reported. The median time to achieve a complete cytogenetic remission was three (range 3-6) months; $90 \%$ and $96 \%$ of patients achieved a complete cytogenetic remission at months 3 and 6 , respectively. In patients who received imatinib $400 \mathrm{mg}$ daily, a complete cytogenetic remission was observed in $45 \%$ at 6 months. ${ }^{46}$ High-dose imatinib (800 mg/daily) produced a complete 
cytogenetic remission in $70 \%$ of patients at 12 months. $^{47}$ This increased rate and onset of cytogenetic response is controversial, but has been associated with less risk of disease progression. Given the durable complete cytogenetic remission rates, as expected, the estimated event-free survival at 24 months was $90 \%$ and the transformation-free survival rate was $98 \%{ }^{46}$ These data continue to demonstrate the efficacy of nilotinib in newly diagnosed patients with chronic phase CML.

A lower nilotinib dose of $300 \mathrm{mg}$ twice daily was evaluated in untreated CML patients in the All-Ireland Cooperative Oncology Research Group 0802 open-label Phase II study. This group investigated the ability of lower dosing to produce an improved adverse event profile. The primary endpoint of this study was complete cytogenetic remission at 6 months, and secondary endpoints included molecular response determined at baseline and at monthly intervals. A new rapid turnaround polymerase chain reaction system, ie, "GeneXpert", was also evaluated. By intent to treat analysis, $64 \%$ (16/25 patients) achieved a complete cytogenetic remission at 3 months and 95\% (19/20 patients) at 6 months. At 6 months, 60\% (12/20 patients) achieved a major molecular remission. Investigators did report that there was a trend to underestimate the $\mathrm{BCR}: \mathrm{ABL} / \mathrm{ABL}$ percentage which overestimates major molecular remission via the GeneXpert system. ${ }^{48}$ Only three patients (12\%) have required an increased dose to $400 \mathrm{mg}$ bid due to suboptimal results. Grade 3/4 hematologic toxicities were minimal, with only two patients (5\%) developing Grade 3 thrombocytopenia. This study continues to confirm nilotinib $300 \mathrm{mg}$ bid is a safe and efficacious option for newly diagnosed CML patients. ${ }^{48}$

In the open-label, multicenter Phase III ENESTnd study, patients were eligible within six months of diagnosis of CML, and were excluded if they had received imatinib or any other treatment (except hydroxyurea or anagrelide) for more than 2 weeks. In this study, patients were randomized in a $1: 1: 1$ ratio to receive imatinib $400 \mathrm{mg}$ daily, nilotinib $300 \mathrm{mg}$ twice daily, or nilotinib $400 \mathrm{mg}$ twice daily. ${ }^{42}$ Randomization for ENESTnd was stratified according to the Sokal risk score. ${ }^{49}$ Patients who had a suboptimal response, as defined by the European Leukemia Net, ${ }^{44}$ could escalate to imatinib $400 \mathrm{mg}$ twice daily. However, patients were not allowed to cross over to other cohorts. The primary endpoint of this investigation was the rate of achievement of a major molecular remission at 12 months. ${ }^{42}$ As with other studies, this was defined as a reduction of at least three log copies of $\mathrm{BCR}-\mathrm{ABL}$ transcripts as compared with baseline (established from the IRIS trial). ${ }^{2,37}$ In this study, all quantitative reversetranscriptase polymerase chain reaction assays were performed in one central laboratory (Molecular MD). Secondary endpoints were the rate of complete cytogenetic remission at 12 months and durability of major molecular remission at 24 months. ${ }^{42}$

A total of 846 patients were enrolled in ENESTnd. Treatment arms were balanced according to age, gender, Sokal risk score, ${ }^{49}$ and median time of diagnosis prior to enrollment. At 12 months, major molecular remission rates were significantly better in patients who received nilotinib $300 \mathrm{mg}$ twice daily (44\%) versus nilotinib $400 \mathrm{mg}$ twice daily (43\%) versus imatinib $400 \mathrm{mg}$ daily $(22 \%) ; P<0.001$ for both comparisons. ${ }^{42}$

Recently, 18-month follow-up data from ENESTnd was presented at the 2010 American Society of Hematology meeting (see Table 2). A complete molecular response was defined by a BCR-ABL transcript level $\leq 0.0032 \%$ (international scale); $21 \%$ and $17 \%$ of patients on nilotinib $300 \mathrm{mg}$ twice daily and nilotinib $400 \mathrm{mg}$ twice daily, respectively, achieved this target, compared with only $6 \%$ of patients in the imatinib group. The secondary endpoint of complete cytogenetic remission rate at 18 months also favored the nilotinib groups, ie, $300 \mathrm{mg}$ twice daily $(85 \%, P<0.001)$ versus nilotinib $400 \mathrm{mg}$ twice daily $(82 \%, P=0.017)$ versus imatinib $400 \mathrm{mg}$ daily (74\%). Furthermore, the progression

Table 2 Updated phase III studies of second generation TKIs in front-line therapy

\begin{tabular}{|c|c|c|c|c|}
\hline & $\mathbf{n}$ & Study arm & CCyR@ @ 8 months & MMR@ @ 8 months \\
\hline \multirow[t]{4}{*}{ ENESTnd ${ }^{50}$ study } & 282 & Nilotinib 300 mg twice daily & 85 & 66 \\
\hline & 281 & Nilotinib 400 mg twice daily & \multirow{2}{*}{$P<0.017$} & $P<0.001$ \\
\hline & 283 & Imatinib 400 mg daily & & $\left.40 \int P<0.001\right)$ \\
\hline & $\mathbf{n}$ & Study arm & CCyR@ 18 months & MMR@ @ 2 months \\
\hline \multirow[t]{2}{*}{ DASISION ${ }^{52}$ study } & 259 & Dasatinib 100 mg daily & \multirow{2}{*}{$P=0.0366$} & \multirow{2}{*}{$P<0.002$} \\
\hline & 260 & Imatinib 400 mg daily & & \\
\hline
\end{tabular}

Abbreviations: CCyR, complete cytogenetic response; MMR, major molecular response. 
of disease rate was significantly lower in the nilotinib groups, ie, $300 \mathrm{mg}$ twice daily $(0.7 \%, P=0.006)$ and $400 \mathrm{mg}$ twice daily $(0.4 \%, P=0.003)$ compared with imatinib $(4.2 \%)$. At 18 months, all three arms produced similar overall survival rates of $98.5 \%(P=0.28), 99.3 \%(P=0.03)$, and $96.9 \%$, respectively. ${ }^{50}$ As follow-up of this study continues, it will be interesting to evaluate the discontinuation rates in the nilotinib arms. To date, discontinuation due to adverse events is $7 \%$ for nilotinib $300 \mathrm{mg}$ twice daily versus $12 \%$ for nilotinib $400 \mathrm{mg}$ twice daily. These promising results suggest that nilotinib should continue to be a new frontline treatment option.

\section{Other second-generation TKIs in frontline therapy}

Although not strictly comparable given the differences in study inclusion criteria, the results of ENESTnd are commonly discussed in relation to DASISION (Dasatinib versus Imatinib Study in Treatment Naïve CML Patients) because both studies evaluated a second-generation TKI against imatinib as frontline therapy for CML. As with nilotinib, dasatinib induced a significantly faster and higher complete cytogenetic remission (dasatinib 77\%, imatinib 66\%; $P=0.007)$ at 12 -month follow-up. The rates of major molecular remission also favored dasatinib (83\% versus $72 \%$; $P=0.001) .{ }^{51}$ A recent 18 -month update of this study continues to demonstrate the superiority of dasatinib with regard to complete cytogenetic remission (78\% versus $70 \%$; $P=0.0366)$. The major molecular remission rate at any time during the study also favored dasatinib (57\% versus $41 \%$; $P=0.0002) .{ }^{52}$ Rates of progression-free survival at this interim analysis were $94.9 \%$ for dasatinib and $93.7 \%$ for imatinib. Fewer patients progressed to accelerated phase or blast phase CML while receiving dasatinib $(n=6[2.3 \%]$ versus $n=9[3.5 \%])$ compared with imatinib.

Interim results of an ongoing randomized, open-label, Phase III study of bosutinib (SKI-606) versus imatinib in newly diagnosed CML patients known as BELA (Bosutinib Efficacy and safety in chronic myeloid LeukemiA) was presented at the 2010 American Society of Hematology meeting. Patients were randomized to bosutinib $500 \mathrm{mg}$ daily or imatinib $400 \mathrm{mg}$ daily. The study did not meet its primary endpoint of superior complete cytogenetic remission at 12 months (bosutinib 70\%, imatinib 68\%; $P=0.601$ ) in the intent to treat population. However, patients did achieve a faster complete cytogenetic remission if receiving bosutinib (13 weeks versus 25 weeks; $P<0.001$ ). As expected, the cytogenetic responses for second-generation TKIs were higher in a frontline setting when compared with the previous Phase II studies performed in imatinib-resistant or imatinibintolerant patients (see Table 3). The BELA study did meet its secondary endpoint. A higher proportion of patients treated with bosutinib achieved higher major molecular remission rates (39\% versus $26 \% ; P=0.006)$. Furthermore, fewer patients $(n=4,1.6 \%)$ who received bosutinib progressed to advanced CML than those on imatinib $(\mathrm{n}=10,3.2 \%)$. Based upon these results, efforts to seek approval for bosutinib by the FDA and European Medicine Agency in newly diagnosed CML patients are underway. ${ }^{53}$

\section{Resistance}

The current National Comprehensive Cancer Network guidelines for CML recommend that a complete hematologic response should be achieved at 3 months, a complete cytogenetic remission or partial cytogenetic response at 6 months, and a complete cytogenetic remission at 12 and 18 months for frontline therapy. ${ }^{1}$ This recommendation is based upon imatinib data, and the National Comprehensive Cancer Network panel recommends the same evaluation points if dasatinib or nilotinib are used as initial therapy. If a patient starts nilotinib as frontline therapy and does not achieve an adequate clinical response, several issues should be considered. Foremost, patient adherence should be addressed. Poor patient

Table 3 Phase II studies of second generation TKIs in imatinib resistant or intolerant CML-CP and -AP patients

\begin{tabular}{|c|c|c|c|c|c|c|c|}
\hline & Author & $\mathbf{n}$ & Dose & Stage of disease & CHR (\%) & MCyR (\%) & CCyR (\%) \\
\hline \multicolumn{8}{|l|}{ Nilotinib } \\
\hline & Kantarjian ${ }^{8}$ & 321 & $400 \mathrm{mg}$ BID & $-\mathrm{CP}$ & 77 & 57 & 41 \\
\hline & leCoutre 9 & 119 & $400 \mathrm{mg}$ BID & $-A P$ & 26 & 29 & 16 \\
\hline \multicolumn{8}{|l|}{ Dasatinib } \\
\hline & Hochhaus ${ }^{10,13}$ & 387 & 70 mg BID & $-\mathrm{CP}$ & 91 & 59 & 49 \\
\hline & Guilhot ${ }^{\prime \prime}$ & 107 & 70 mg BID & $-A P$ & 39 & 33 & 24 \\
\hline \multicolumn{8}{|l|}{ Bosutinib } \\
\hline & Cortes $^{12}$ & 283 & 500 mg Qday & $-\mathrm{CP}$ & 79 & 40 & 29 \\
\hline & Gambacorti-Passerini ${ }^{14}$ & 44 & 500 mg Qday & $-A P$ & 64 & 69 & 14 \\
\hline
\end{tabular}

Abbreviations: CML-CP, chronic phase; CML-AP, accelerated phase; CHR, complete hematologic response; MCyR, major cytogenetic response; CCyR, complete cytogenetic response. 
adherence has been associated with suboptimal outcomes in patients receiving imatinib. ${ }^{54-56}$ If $\mathrm{BCR}-\mathrm{ABL}$ transcripts continue to increase despite patient adherence, other factors, such as the development of point mutations, increased expression of BCR-ABL, drug interactions with CYP3A4 inducers, decreased bioavailability, and P-glycoprotein expression should be considered. ${ }^{57,58}$ Currently there are no available guidelines which suggest specific increases of BCR-ABL transcripts that warrant a change in current therapy. It is important to note that the presence of a BCR-ABL mutant does not necessarily lead to resistance. Although a 2-3-fold increase in BCR-ABL has been suggested to be indicative of kinase mutations, ${ }^{59}$ mutational analysis screening should be performed if inadequate response to nilotinib is reported.

Over 50 point mutations with varying degrees of resistance have been identified with imatinib. ${ }^{58,60}$ Recent clinical data have suggested that approximately $50 \%-90 \%$ of patients with imatinib resistance will have a BCR-ABL kinase mutation. ${ }^{60,61}$ In recent years, second-generation TKIs have provided a therapeutic option for those harboring specific BCR-ABL mutations which lead to imatinib resistance. In this setting, the specific mutation contributes to the sequential therapeutic choice of which TKI to select. As these agents transition themselves to become potential firstline treatment options, it will become important to continue to assess BCRABL kinase mutational status during therapy. ABL kinase mutations are generally described by location and are numbered by specific amino acid residues. ${ }^{62}$ The ABL kinase domain consists of the P-loop, activation loop, and the catalytic domain. ${ }^{63}$ Mutations can occur via direct inhibition by altering an amino acid, which impairs drug binding without affecting adenosine triphosphate binding. An example of this is the substitution of phenylalanine for leucine mutation at codon 317. Mutations can also occur in amino acid residues which are involved in the conformational change of BCR-ABL. For example, a tyrosine to histidine mutation at 253 break hydrogen bond interactions specific for distortion of the P-loop. ${ }^{61}$ X-ray crystallographic analysis of multiple mutant ABL alleles in imatinib-resistant patients was essential for the screening and development of second-generation TKIs. In the case of nilotinib, a N-methylpiperazine ring that participated in hydrogen bonding with Ile360 and His361 in the imatinib molecule was replaced. Whereas imatinib requires six hydrogen bonds to stabilize binding, nilotinib requires only four. This alteration increased the affinity for the inactive conformation of BCR-ABL by $20-30$-fold..$^{20,64}$ Despite this increased potency, resistance can still occur.
Mutations that are highly resistant $\left(\mathrm{IC}_{50}>150 \mathrm{nM}\right)$ to nilotinib include $\mathrm{Y} 253 \mathrm{H}, \mathrm{E} 255 \mathrm{~K} / \mathrm{V}, \mathrm{F} 359 \mathrm{C} / \mathrm{V}$, and T315I. ${ }^{65-68}$ In a multivariate analysis, chronic phase CML patients with E255K/V, Y253H, or F359C/V had a significantly shorter progression-free survival (hazards ratio 6.097, $P \leq 0.0001$ ) with nilotinib following imatinib failure. ${ }^{69}$ Hughes et al also reported that mutations $\mathrm{E} 255 \mathrm{~K} / \mathrm{V}, \mathrm{Y} 253 \mathrm{H}$, and $\mathrm{F} 359 \mathrm{C} / \mathrm{V}$ were associated with less in vitro sensitivity and lower clinical response rates. Furthermore, none of these patients were able to obtain a complete cytogenetic remission at 12 months of therapy, six (19\%) achieved a molecular and cytogenetic remission, and $10(32 \%)$ achieved a complete hematologic response. ${ }^{66}$ Patients who harbor the T315I mutation are not responsive to imatinib, nilotinib, or dasatinib. ${ }^{65}$ This mutation usually affects patients in advanced stages of accelerated phase/blast crisis CML as well as acute lymphoblastic leukemia. These patients may respond to investigational agents, such as AP24534 or omacetaxine, and should pursue allogeneic stem cell transplantation. ${ }^{70-72}$ There has been some concern about selecting for T315I with the increased use of second-generation TKIs. To date, this has not been demonstrated. Other mutations that have varying degrees of resistance to nilotinib include G250E, F359V, L248V, Q252H, Y253F, E279K, F317L, L384M, H396P, and H396R. ${ }^{65}$ Interestingly, nilotinib failure can be seen in P-loop mutations, such as the previously mentioned Y253H and E255K/V. ${ }^{65,73,74}$ However, other P-loop mutants (L248V, G250E, and Q252H) have demonstrated in vitro sensitivity to nilotinib. Jabbour et $\mathrm{al}^{75}$ reported no differences in overall survival with the presence of P-loop mutations in patients who received second-generation TKIs following imatinib. The G250E mutation classification is controversial. Some classify this mutation as resistant to imatinib, dasatinib, nilotinib, and bosutinib, ${ }^{65}$ whereas O'Hare et $\mathrm{al}^{76}$ report this mutation to be sensitive $\left(\mathrm{IC}_{50}\right.$ $48 \mathrm{nM}$ for nilotinib and $1.8 \mathrm{nM}$ for dasatinib) to secondgeneration TKIs. The mutation F317L located in the adenosine triphosphate binding region is associated with resistance to dasatinib, and these patients may respond positively to nilotinib. ${ }^{65,77,78}$

Data on resistance with second-generation TKIs used frontline will continue to emerge as the relevant studies mature. There is a concern that earlier exposure to nilotinib could result in new and more resistant mutations. Early data presented at the 2010 American Society of Hematology meeting appear to be promising. In ENESTnd, with a median follow-up of 18 months, mutational testing was performed in 164,171 , and 199 pts in the nilotinib $300 \mathrm{mg}$ bid, $400 \mathrm{mg}$ 
bid, and imatinib arms, respectively. Patients who developed a BCR-ABL mutation were as follows: nilotinib $300 \mathrm{mg}$ twice daily (8 [3\%]), nilotinib $400 \mathrm{mg}$ twice daily (5 [2\%]), and imatinib (16 [6\%]). The eight BCR-ABL mutations in the nilotinib $300 \mathrm{mg}$ twice daily group were identified in six patients. These included Y253H, Y253H/F359V, E255K/ T315I, T315I, F359V, and E2459K. Y253H, E255K, and F359V were deemed less sensitive, but not inherently resistant, as was the T315I identified in three patients receiving nilotinib. Six of 16 imatinib-treated patients (38\%) with BCR-ABL mutations progressed to accelerated phase/blast crisis CML, as compared with 1/13 (8\%) of nilotinib-treated patients. ${ }^{79}$ Investigators at MD Anderson Cancer Center also recently presented their institutional history with nilotinib $(\mathrm{n}=90)$ and dasatinib $(\mathrm{n}=82)$ used in frontline CML therapy or for accelerated phase CML patients who had not been previously treated. In this retrospective analysis, 13 (16\%) discontinued nilotinib therapy due to adverse events, progression, or other reasons. Three patients (two of whom were treated during an accelerated phase) receiving nilotinib progressed to blast crisis. Fourteen patients had BCR-ABL mutation analysis performed. Only two mutants (F359C and $\mathrm{Y} 253 \mathrm{H})$ were reported. ${ }^{80}$ Cortes et $\mathrm{al}^{46}$ reported that one patient who had never achieved a major molecular remission developed a E255K mutation after 8 months on frontline nilotinib therapy. Two further patients in this study discontinued nilotinib due to intolerance and later progressed to blast crisis, one of whom developed a F359C mutation. Although BCR-ABL mutations are still being identified despite nilotinib use in frontline therapy, accounting for the number of patients receiving this therapy and comparing imatinib data, it does not appear that the use of nilotinib is associated with an increased risk of inducing BCR-ABL mutations.

\section{Tolerability}

Nilotinib is well tolerated with a favorable risk-benefit profile. Most adverse events are categorized as Grade 1/2 toxicities and are manageable. These toxicities include rash, pruritus, and headache. The most common Grade 3/4 nonhematologic events include biochemical abnormalities, such as elevations in bilirubin, amylase, and lipase. These adverse events are a common cause of dose interruption or discontinuation. ${ }^{81}$ Biochemical abnormalities, such as hyperglycemia and hypophosphatemia, are associated with nilotinib. As with other oral TKIs used to treat CML, myelosuppression may be severe and require dose reduction. Secondgeneration TKIs have been associated with higher Grade
3/4 neutropenia and thrombocytopenia rates, but these agents were predominantly evaluated in imatinib-resistant patients who would be more likely to have impaired hematopoiesis. ${ }^{82}$ Nilotinib is associated with less fluid retention when compared with imatinib and dasatinib. ${ }^{83}$ Furthermore, nilotinib is less likely to be associated with pleural or pericardial effusions ( $<1 \%$ of Grade $3 / 4$ events) when compared with dasatinib. Although uncommon, cardiac toxicities, such as congestive heart failure, left ventricular dysfunction, and QT prolongation, have also been observed. ${ }^{81}$

\section{Nonhematologic toxicity}

The most frequently reported all-grade nonhematologic adverse events associated with nilotinib $400 \mathrm{mg}$ twice daily in imatinib-resistant or imatinib-intolerant patients include rash $(33 \%)$, headache $(31 \%)$, pruritus $(29 \%)$, and fatigue $(28 \%) .{ }^{81}$ Serum biochemical abnormalities are the most clinically relevant adverse events. Le Coutre et $\mathrm{al}^{9}$ reported Grade 3/4 lipase elevations in 18\% of 119 accelerated phase CML patients in a Phase II study. In this study, Grade 3/4 amylase elevations occurred in 2\% of patients, one of whom discontinued therapy due to pancreatitis. Hepatic transaminase elevations $(<2 \%$ Grade $3 / 4)$ have also been reported. Hyperbilirubinemia has also been observed, but is usually self-limiting despite continued treatment. ${ }^{8}$ It is recommended that patients with $\geq$ Grade 3 elevations in amylase, bilirubin, or transaminases should temporarily discontinue therapy and resume treatment at $400 \mathrm{mg}$ daily. ${ }^{81}$

Cardiac toxicity, namely QT prolongation, has been reported with nilotinib. Kantarjian et $\mathrm{al}^{8}$ in a Phase I study analyzed more than 2200 electrocardiograms from 119 patients. Mean increases of Fredericia's corrected QT interval (QTc) were 5-15 msec in patients who received nilotinib. Le Coutre et $\mathrm{al}^{9}$ observed QTc increases $>60 \mathrm{msec}$ in $4 \%$ of patients, but no episodes of torsades de pointes were reported. In contrast, mean changes of QTc on dasatinib were 3-6 msec, whereas imatinib has not been reported to prolong the QTc interval. ${ }^{82}$ To date, five sudden deaths have been reported in clinical studies $(n=867 ; 0.6 \%)$. Patients with hypokalemia or hypophosphatemia should have electrolyte abnormalities corrected prior to initiation of nilotinib. Furthermore, concurrent use of CPY3A4 inhibitors should be avoided to prevent possible increases in the QT interval. The manufacturer recommends that electrocardiograms be performed at baseline, a week following initiation of therapy, and periodically thereafter. ${ }^{81}$ 
Although imatinib and nilotinib are structurally similar, their well known toxicities such as fluid retention, edema, and weight gain, are less common with nilotinib. ${ }^{81,84}$ In Phase II clinical trials evaluating nilotinib, all-grade pleural effusions were reported in $<1 \%$ of patients. ${ }^{89}$ In contrast, pleural effusions were reported in $27 \%-31 \%$ of patients in clinical studies evaluating dasatinib $140 \mathrm{mg}$ daily. ${ }^{10,85}$ However, recent Phase III trials evaluating dasatinib $100 \mathrm{mg}$ daily have reported a lower all-grade incidence of pleural effusion (7\%-10\%)..$^{51,86}$ It has been proposed that nilotinib is associated with less fluid retention because it has a weaker affinity for platelet-derived growth factor beta than does imatinib and dasatinib $\left(\mathrm{IC}_{50}\right.$ for platelet-derived growth factor $53 \mathrm{nM}$ for nilotinib, $39 \mathrm{nM}$ for imatinib, and $28 \mathrm{nM}$ for dasatinib). ${ }^{20,83,87}$ Platelet-derived growth factor-beta receptors have been shown to regulate interstitial fluid pressure and thus control transport from the vasculature into the extracellular space.$^{88}$ Thus, possible "off-target" inhibition of these receptors may explain this higher incidence of peripheral and pulmonary edema. However, an immune-mediated etiology has also been proposed due to lymphocyte-predominant exudative effusions secondary to dasatinib use..$^{83,89}$ In a retrospective study, $62 \mathrm{CML}$ patients treated with dasatinib were evaluated to identify predictive factors. In a multivariate analysis, independent predictors of pleural effusions were skin rash (relative risk [RR] 5.3, 95\% confidence interval [CI]: 1.9-14.6; $P<0.0001$ ), previous history of autoimmune disease (RR 4.4, 95\% CI: 1.3-14; $P<0.015$ ), and hypercholesterolemia (RR 3.5, 95\% CI: $1.8-14.6, P=0.037$ ). ${ }^{90}$ Other factors which have been implicated include previous lung problems (infection/smoking), hypertension, advanced disease, and those maintained on dasatinib $70 \mathrm{mg}$ bid. ${ }^{91,92}$ The development of pleural effusions appears to be multifactorial, and offers a potential selective advantage for nilotinib as frontline therapy in certain patient populations.

\section{Hematologic toxicity}

Neutropenia and thrombocytopenia were the most commonly reported hematologic toxicities in Phase II trials evaluating nilotinib in imatinib-resistant or imatinib-intolerant patients. In patients with chronic phase CML $(\mathrm{n}=318)$, nilotinib $400 \mathrm{mg}$ twice daily was associated with $\geq$ Grade 3 neutropenia (28\%) and thrombocytopenia (28\%). ${ }^{93}$ Increased $\geq$ Grade 3 rates of myelosuppression (neutropenia 37\%, thrombocytopenia $37 \%)$ have been reported in patients $(n=119)$ with advanced accelerated phase CML. ${ }^{9}$ Dose reductions are not warranted for Grade 1/2 toxicities. In patients receiving nilotinib $400 \mathrm{mg}$ twice daily for resistant or intolerant chronic or accelerated phase CML, an absolute neutrophil count $<1 \times 10^{9} / \mathrm{L}$ or platelet count $<50 \times 10^{9} / \mathrm{L}$ does requires transient cessation and possible dose reduction. ${ }^{81}$ In a retrospective analysis performed at MD Anderson Cancer Center, dose reductions/interruptions of both nilotinib and dasatinib were analyzed in all-phase CML patients. A total of 280 patients were analyzed, and nilotinib was used in $129(46 \%)$ patients. The most common reason for dose reduction was thrombocytopenia (31\%), elevated bilirubin (16\%), and neutropenia (14\%). Interestingly, in this analysis, dose reductions/interruptions had no impact on response rates for either agent. These data led the authors to postulate that lower doses of either TKI could be used in CML. ${ }^{94}$ Data from the ENESTnd study confirmed that a lower dose of nilotinib (600 mg daily) was as efficacious, may have less toxicity, and could be more cost-effective. ${ }^{42}$

\section{Specific toxicity in frontline therapy}

Rosti et $\mathrm{al}{ }^{43}$ evaluated nilotinib $400 \mathrm{mg}$ twice daily in previously untreated patients with chronic phase CML. Similar rates of all-grade nonhematologic toxicities were observed, including skin rash (42\%), bone/muscle pain (41\%), headache $(30 \%)$, fatigue (22\%), and pruritus (21\%). Grade 3 hyperbilirubinemia was noted in $16 \%$ of patients. Kantarjian et al ${ }^{8}$ reported that $9 \%$ of previously treated patients experienced this Grade 3/4 toxicity. Electrocardiographic monitoring was performed, and transient abnormalities were observed in 16 patients, but none had a QT interval $>500 \mathrm{msec}$. Hematological events were exceedingly rare, with only $4 \%$ and $2 \%$ experiencing Grade 3 or 4 neutropenia and thrombocytopenia, respectively. Temporary dose interruptions were needed in $52 \%$ of patients, for an average duration of 19 days. Cortes et $\mathrm{a}^{46}$ reported higher rates of myelosuppression, but this was comparable with previous imatinib data in untreated patients. Nilotinib was associated with Grade 3/4 anemia (5\%), neutropenia (12\%), and thrombocytopenia (11\%). Grade 3/4 toxicities observed for imatinib $400 \mathrm{mg}$ daily in the IRIS trial comprised anemia (3\%), neutropenia $(14 \%)$, and thrombocytopenia ( $8 \%) .^{2}$ In ENESTnd, the nilotinib $300 \mathrm{mg}$ twice daily arm had Grade $3 / 4$ toxicities of anemia (5\%), neutropenia (12\%), and thrombocytopenia (10\%), respectively, compared with the imatinib $400 \mathrm{mg}$ daily arm, in which rates of these toxicities were $5 \%, 20 \%$, and $9 \%$, respectively. Furthermore, the nilotinib $300 \mathrm{mg}$ twice daily arm had the lowest discontinuation rate $(5 \%)$ due to adverse events ${ }^{42}$ (see Table 4 for comparison of adverse events on nilotinib and dasatinib in the Phase III studies). 
Table 4 Selected adverse event profile of BCR-ABL TK inhibitors in front-line CML therapy

\begin{tabular}{|c|c|c|c|c|c|c|c|c|}
\hline & \multicolumn{2}{|c|}{$\begin{array}{l}\text { Imatinib } 400 \text { mg daily }{ }^{42} \\
(n=280)\end{array}$} & \multicolumn{2}{|c|}{$\begin{array}{l}\text { Dasatinib } 100 \mathrm{mg} \\
\text { daily }^{51}(\mathrm{n}=258)\end{array}$} & \multicolumn{2}{|c|}{$\begin{array}{l}\text { Nilotinib } 300 \mathrm{mg} \\
\text { BID }^{42}(\mathrm{n}=279)\end{array}$} & \multicolumn{2}{|c|}{$\begin{array}{l}\text { Nilotinib } 400 \mathrm{mg} \\
\text { BID }^{42}(\mathrm{n}=277)\end{array}$} \\
\hline & $\begin{array}{l}\text { All Grades } \\
\%\end{array}$ & $\begin{array}{l}\text { Grades 3-4 } \\
\%\end{array}$ & $\begin{array}{l}\text { All Grades } \\
\%\end{array}$ & $\begin{array}{l}\text { Grades 3-4 } \\
\%\end{array}$ & $\begin{array}{l}\text { All Grades } \\
\%\end{array}$ & $\begin{array}{l}\text { Grades 3-4 } \\
\%\end{array}$ & $\begin{array}{l}\text { All Grades } \\
\%\end{array}$ & $\begin{array}{l}\text { Grades 3-4 } \\
\%\end{array}$ \\
\hline Neutropenia & 68 & 20 & 65 & 21 & 43 & 12 & 38 & 10 \\
\hline Thrombocytopenia & 56 & 19 & 70 & 19 & 48 & 10 & 49 & 12 \\
\hline Anemia & 47 & 5 & 90 & 10 & 38 & 3 & 38 & 3 \\
\hline Nausea & 31 & 0 & 8 & 0 & II & $<1$ & 19 & I \\
\hline Vomiting & 14 & 0 & 5 & 0 & 5 & 0 & 9 & I \\
\hline Rash & II & I & 11 & 0 & 31 & $<1$ & 36 & 3 \\
\hline Arthalgia/Myalgia & -110 & -10 & -16 & -10 & -110 & $<1$ & -110 & -10 \\
\hline Peripheral edema & 14 & 0 & NR & NR & 5 & 0 & 5 & 0 \\
\hline Pleural effusion & NR & NR & 10 & 0 & NR & NR & NR & NR \\
\hline
\end{tabular}

Abbreviation: NR, not reported.

These observations suggest that nilotinib is a safe frontline treatment option for patients with chronic phase CML.

\section{Quality of life}

The advent of the first-generation and second-generation TKIs in the treatment of CML has dramatically improved the quality of life of patients afflicted with this disease when compared with previous treatments, such as interferon and oral busulfan. Participants in the IRIS trial completed the Functional Assessment of Cancer Therapy-Biologic Response Modifiers (FACT-BRM) which is a validated 40-question instrument. ${ }^{95}$ Patients completed the FACT-BRM at baseline, and at months 1, 2, 3, 4, 5, 6, 9, and 12 following initiation of treatment with either imatinib or cytarabineinterferon. Across all baseline data collection points, the imatinib arm $(\mathrm{n}=530)$ performed significantly $(P<0.001)$ better in terms of the Trial Outcome Index score than the cytarabineinterferon group $(\mathrm{n}=519) .{ }^{96}$ In patients who were intolerant to imatinib therapy, second-generation TKIs have provided clinical benefit, with a generally improved toxicity profile. Formal comparative quality of life and economic analysis are needed for these agents. An ongoing study (NCT00980018) is assessing quality of life from baseline to the end of cycles $1,3,6,9$, and 12 in patients switching from imatinib to nilotinib. This investigation will assess the change in the MD Anderson Symptom Inventory Module (MDASI-CML) symptom-burden tool which is currently under evaluation. ${ }^{97}$ The MDASI-CML rates the severity of symptoms (13 items) and interference with activities of daily living (six items) ${ }^{98}$ Ongoing research into patient-reported symptoms and supportive care methods continues. This will be crucial for the future of treating CML. Patients may be required to tolerate chronic toxicities from indefinite TKI therapy.

\section{Conclusion}

The development of BCR-ABL kinase inhibitors which was initiated in the mid-1990s has been tremendously successful. ${ }^{99}$ The establishment of imatinib in 2001 as frontline therapy transformed the treatment of CML dramatically. Ten years later, new questions have emerged. Foremost, should frontline treatment of CML change to a second-generation TKI? The answer to this question is complex and continues to be examined. As we continue to follow original IRIS study participants, impressive $85 \%$ overall survival and $81 \%$ event-free survival rates have been demonstrated with imatinib at 8 years. ${ }^{5}$ In addition, the estimated annual risk of treatment failure was $3.3 \%, 7.5 \%, 4.8 \%, 1.5 \%$, and $0.9 \%$ in the first 5 years of therapy. ${ }^{3}$ Some would suggest continuing imatinib as frontline therapy due to its notable efficacy, more experience with its use, and the fact that, if a patient become resistant or intolerant, several second-generation TKIs are available. However, some have debated whether imatinib $400 \mathrm{mg}$ daily should be the recommended dose for newly diagnosed CML patients. Trials evaluating higher doses of imatinib (600 or $800 \mathrm{mg}$ daily) have produced a deeper molecular response. Kantarjian et al ${ }^{100}$ evaluated imatinib $800 \mathrm{mg}$ daily in newly diagnosed chronic phase patients $(\mathrm{n}=114)$. High-dose imatinib produced improved complete cytogenetic remission $(P=0.0005)$, major molecular remission $(P=0.00001)$, and complete molecular response $(P=0.001)$ compared with standard imatinib. Achieving a cytogenetic and molecular response, and at what time point, is a significant concern. For example, none of the patients who achieved a complete cytogenetic remission at 12 months with imatinib progressed to the accelerated phase or blast crisis. ${ }^{5}$ This suggests that if a more potent $\mathrm{BCR}-\mathrm{ABL}$ inhibitor, such as nilotinib, was used in frontline 
therapy, potentially fewer patients would progress to advanced disease.

It could be assumed that the ability of nilotinib to produce deeper molecular responses would be associated with improved progression-free survival and overall survival. However, a lack of correlation between achieving a molecular response and improving overall survival has been reported in patients receiving imatinib. These same investigators did show that patients who achieved a complete cytogenetic remission and major molecular remission (continuously for 12 months) had improved progression-free survival but not overall survival. ${ }^{101}$ DeLavallade et al ${ }^{102}$ published similar results, whereby newly diagnosed patients who obtained a complete cytogenetic remission by 12 months had better progression-free survival and overall survival, but achieving a major molecular remission confirmed no advantage. Given the differences in major molecular remission (see Table 2) between nilotinib and imatinib in updated ENESTnd data, it will be interesting to evaluate overall survival in those patients which achieved a major molecular remission. Currently, the estimated overall survival in the intent to treat population for nilotinib $300 \mathrm{mg}$ twice daily is $98.5 \%$ and for imatinib is $96.9 \%$. Given the lack of significant overall survival benefit at the approved $300 \mathrm{mg}$ twice daily dose, factors such as fewer CML-related deaths, reduced progression to accelerated phase/blast crisis (particularly including clonal evolution), and lower incidence of BCR-ABL mutations with nilotinib, all merit the use of nilotinib in a frontline setting. ${ }^{50,79}$

With the emergence of second-generation TKIs, investigations of combination therapy and a very active drug development pipeline that includes a pan-BCR-ABL inhibitor (ponatinib) ${ }^{103}$ omacetaxine, ${ }^{71}$ Aurora-kinase inhibitors, ${ }^{104}$ farnesyltransferase inhibitors, ${ }^{105}$ and histone deacetylase inhibitors, ${ }^{106,107}$ hope for a potential "cure" continues. Longterm outcomes for second-generation TKIs used in frontline treatment will continue to emerge. We would encourage patients who are experiencing optimal responses, as defined by practice recommendations, to continue imatinib therapy. However, if patients experience suboptimal response or intolerance to imatinib, a switch to a second-generation TKI is warranted. The decision as to which particular agent should be individualized and take into consideration patient-specific information. Patients with a history of hypertension, smoking, cardiac problems, chronic obstructive pulmonary disease, and advanced disease (more than accelerated phase) would be better candidates for nilotinib, to avoid the possible development of pleural effusions. Monitoring is warranted in nilotinib or dasatinib patients with a previous history of congestive heart failure or left ventricular dysfunction because QTc elongation has been noted with both agents. For diabetes patients, hyperglycemia needs to be carefully monitored because it could be exacerbated with the initiation of nilotinib. In conclusion, nilotinib $300 \mathrm{mg}$ twice daily is a well tolerated and highly effective in newly diagnosed CML patients. Nilotinib represents a new standard of care for CML patients.

\section{Disclosure}

The authors have no conflicts of interest to disclose.

\section{References}

1. National Comprehensive Cancer Network ( $\mathrm{NCCN}$ ) Practice Guidelines (version 2.2011): Chronic myelogenous leukemia. http://www.nccn.org/ professionals/physician_gls/PDF/cmlpdf. Accessed October 10, 2010.

2. O'Brien SG, Guilhot F, Larson RA, et al. Imatinib compared with interferon and low-dose cytarabine for newly diagnosed chronic-phase chronic myeloid leukemia. N Engl J Med. 2003;348:994-1004.

3. Druker BJ, Guilhot F, O'Brien SG, et al. Five-year follow-up of patients receiving imatinib for chronic myeloid leukemia. $N$ Engl J Med. 2006; 355:2408-2417.

4. Hochhaus A, Druker BJ, Larson RA, et al. IRIS 6-year follow-up: Sustained survival and declining annual rate of transformation in patiens with newly diagnosed chronic myeloid leukemia in chronic phase (CML-CP) treated with imatinib. Blood. 2007;110:15.

5. Deininger M, O'Brien SG, Guilhot F, et al. International Randomized Study of Interferon Vs STI571 (IRIS) 8-year follow up: Sustained survival and low risk for progression or events in patients with newly diagnosed chronic myeloid leukemia in chronic phase (CML-CP) treated with imatinib. Blood. 2009;114:1126.

6. Hamdan MYS, L., Oliveria S, Campbell U, et al. Discontinuation and dose modfication of imatinib in clinical practice. J Clin Oncol. 2007; $25: 7045$

7. Jabbour E, Kantarjian HM, Jones D, et al. Imatinib mesylate dose escalation is associated with durable responses in patients with chronic myeloid leukemia after cytogenetic failure on standard-dose imatinib therapy. Blood. 2009;113:2154-2160.

8. Kantarjian HM, Giles F, Gattermann N, et al. Nilotinib (formerly AMN107), a highly selective BCR-ABL tyrosine kinase inhibitor, is effective in patients with Philadelphia chromosome-positive chronic myelogenous leukemia in chronic phase following imatinib resistance and intolerance. Blood. 2007;110:3540-3546.

9. Le Coutre P, Ottmann OG, Giles F, et al. Nilotinib (formerly AMN107), a highly selective BCR-ABL tyrosine kinase inhibitor, is active in patients with imatinib-resistant or -intolerant accelerated-phase chronic myelogenous leukemia. Blood. 2008;111:1834-1839.

10. Hochhaus A, Kantarjian HM, Baccarani M, et al. Dasatinib induces notable hematologic and cytogenetic responses in chronic-phase chronic myeloid leukemia after failure of imatinib therapy. Blood. 2007;109: 2303-2309.

11. Guilhot F, Apperley J, Kim DW, et al. Dasatinib induces significant hematologic and cytogenetic responses in patients with imatinibresistant or -intolerant chronic myeloid leukemia in accelerated phase. Blood. 2007;109:4143-4150.

12. Cortes J, Kantarjian HM, Kim DW, et al. Efficacy and safety of bosutinib (SKI-606) in patients with chronic phase (CP) $\mathrm{Ph}+$ chronic myelogenous leukemia (CML) with resistance or intolerance to imatinib. Blood. 2008; 112:1098. 
13. Hochhaus A, Baccarani M, Deininger M, et al. Dasatinib induces durable cytogenetic responses in patients with chronic myelogenous leukemia in chronic phase with resistance or intolerance to imatinib. Leukemia. 2008;22:1200-1206.

14. Gambacorti-Passerini C, Pogliani EM, Baccarani M, et al. Bosutinib (SKI-606) demonstrates clinical activity and is well tolerated in patients with AP and BP CML and Ph+ ALL. Blood. 2008;112:1101.

15. Kurzrock R, Gutterman JU, Talpaz M. The molecular genetics of Philadelphia chromosome-positive leukemias. N Engl J Med. 1988;319: 990-998.

16. Faderl S, Jeha S, Kantarjian HM. The biology and therapy of adult acute lymphoblastic leukemia. Cancer. 2003;98:1337-1354.

17. Druker BJ, Talpaz M, Resta DJ, et al. Efficacy and safety of a specific inhibitor of the BCR-ABL tyrosine kinase in chronic myeloid leukemia. N Engl J Med. 2001;344:1031-1037.

18. Druker BJ, Lydon NB. Lessons learned from the development of an ABL tyrosine kinase inhibitor for chronic myelogenous leukemia. J Clin Invest. 2000;105:3-7.

19. Cowan-Jacob SW, Guez V, Fendrich G, et al. Imatinib (STI571) resistance in chronic myelogenous leukemia: Molecular basis of the underlying mechanisms and potential strategies for treatment. Mini Rev Med Chem. 2004;4:285-299.

20. Weisberg E, Manley PW, Breitenstein W, et al. Characterization of AMN107, a selective inhibitor of native and mutant Bcr-Abl. Cancer Cell. 2005;7:129-141.

21. Quintas-Cardama A, Kantarjian H, Cortes J. Flying under the radar: The new wave of BCR-ABL inhibitors. Nat Rev Drug Discov. 2007;6: 834-838.

22. Manley PW, Drueckes P, Fendrich G, et al. Extended kinase profile and properties of the protein kinase inhibitor nilotinib. Biochim Biophys Acta. 2010;1804:445-453.

23. Warmuth M, Danhauser-Riedl S, Hallek M. Molecular pathogenesis of chronic myeloid leukemia: Implications for new therapeutic strategies. Ann Hematol. 1999;78:49-64.

24. Hu Y, Liu Y, Pelletier S, et al. Requirement of Src kinases Lyn, Hck and Fgr for BCR-ABL1-induced B-lymphoblastic leukemia but not chronic myeloid leukemia. Nat Genet. 2004;36:453-461.

25. Mahon FX, Hayette S, Lagarde V, et al. Evidence that resistance to nilotinib may be due to BCR-ABL, Pgp, or Src kinase overexpression. Cancer Res. 2008;68:9809-9816.

26. Saijo K, Schmedt C, Su IH, et al. Essential role of Src-family protein tyrosine kinases in NF-kappaB activation during B cell development. Nat Immunol. 2003;4:274-279.

27. Hibbs ML, Tarlinton DM, Armes J, et al. Multiple defects in the immune system of Lyn-deficient mice, culminating in autoimmune disease. Cell. 1995;83:301-311.

28. Harder KW, Quilici C, Naik E, et al. Perturbed myelo/erythropoiesis in Lyn-deficient mice is similar to that in mice lacking the inhibitory phosphatases SHP-1 and SHIP-1. Blood. 2004;104:3901-3910.

29. Carpiuc KT, Snedecor SJ, Liou SY, Botteman MF. Incidence of grade 3/4 adverse events in imatinib resistant/intolerant chronic phase CML (CP-CML): A comparison of nilotinib and dasatinib. Presented at the 2007 ASCO annual meeting, Chicago, IL, May 31-June 3, 2007.

30. Snedecor SJ, Carpiuc KT, Liou SY, Botteman MF. Grade 3/4 adverse events (AEs) of second generation tyrosine kinase inhibitors (TKIs) for imatinib resistant/intolerant patients in accelerated phase CML (AP-CML). J Clin Oncol. 2007;25:Abstr 17525.

31. Baccarani M, Cortes J, Pane F, et al. Chronic myeloid leukemia: An update of concepts and management recommendations of European LeukemiaNet. J Clin Oncol. 2009;27:6041-6051.

32. Cortes J, Quintas-Cardama A, Kantarjian HM. Monitoring molecular response in chronic myeloid leukemia. Cancer. October 19, 2010. [Epub ahead of print].

33. Landstrom AP, Ketterling RP, Knudson RA, et al. Utility of peripheral blood dual color, double fusion fluorescent in situ hybridization for $\mathrm{BCR} / \mathrm{ABL}$ fusion to assess cytogenetic remission status in chronic myeloid leukemia. Leuk Lymphoma. 2006;47:2055-2061.
34. Douet-Guilbert N, Morel F, Le Charpentier T, et al. Interphase FISH for follow-up of Philadelphia chromosome-positive chronic myeloid leukemia treatment. Anticancer Res. 2004;24:2535-2539.

35. Seong DC, Kantarjian HM, Ro JY, et al. Hypermetaphase fluorescence in situ hybridization for quantitative monitoring of Philadelphia chromosome-positive cells in patients with chronic myelogenous leukemia during treatment. Blood. 1995;86:2343-2349.

36. Hughes TP, Kaeda J, Branford S, et al. Frequency of major molecular responses to imatinib or interferon alfa plus cytarabine in newly diagnosed chronic myeloid leukemia. N Engl J Med. 2003;349: 1423-1432.

37. Hughes T, Deininger M, Hochhaus A, et al. Monitoring CML patients responding to treatment with tyrosine kinase inhibitors: Review and recommendations for harmonizing current methodology for detecting BCR-ABL transcripts and kinase domain mutations and for expressing results. Blood. 2006;108:28-37.

38. Branford S, Cross NC, Hochhaus A, et al. Rationale for the recommendations for harmonizing current methodology for detecting BCRABL transcripts in patients with chronic myeloid leukaemia. Leukemia. 2006;20:1925-1930.

39. Cross NC. Standardisation of molecular monitoring for chronic myeloid leukaemia. Best Pract Res Clin Haematol. 2009;22:355-365.

40. Quintas-Cardama A, Kantarjian H, Jones D, et al. Delayed achievement of cytogenetic and molecular response is associated with increased risk of progression among patients with chronic myeloid leukemia in early chronic phase receiving high-dose or standard-dose imatinib therapy. Blood. 2009;113:6315-6321.

41. Kantarjian H, O'Brien S, Jabbour E, et al. Different definitions of progression-free survival (PFS) and event-free survival (EFS) may result in perceived but not real differences in long-term outcome when comparing trials in chronic myeloid leukemia (CML). Blood. 2010; 116:672.

42. Saglio G, Kim DW, Issaragrisil S, et al. Nilotinib versus imatinib for newly diagnosed chronic myeloid leukemia. N Engl J Med. 2010;362: 2251-2259.

43. Rosti G, Palandri F, Castagnetti F, et al. Nilotinib for the frontline treatment of $\mathrm{Ph}(+)$ chronic myeloid leukemia. Blood. 2009;114: 4933-4938.

44. Baccarani M, Saglio G, Goldman J, et al. Evolving concepts in the management of chronic myeloid leukemia: Recommendations from an expert panel on behalf of the European LeukemiaNet. Blood. 2006;108: 1809-1820.

45. Rosti G, Castagnetti F, Palandri F, et al. Nilotinib $800 \mathrm{mg}$ daily as frontline therapy of $\mathrm{Ph}+$ chronic myeloid leukemia: Dose delivered and safety profile for the GIMEMA CML working party. Blood. 2009; 114:2205.

46. Cortes JE, Jones D, O'Brien S, et al. Nilotinib as front-line treatment for patients with chronic myeloid leukemia in early chronic phase. J Clin Oncol. 2010;28:392-397.

47. Cortes J, Baccarani M, Guilhot F. A phase III, randomized, open-label study of $400 \mathrm{mg}$ versus $800 \mathrm{mg}$ of imatinib mesylate (IM) in patients (pts) with newly diagnosed, previously untreated chronic myeloid leukemia in chronic phase (CML-CP) using molecular endpoints: 1 year results of TOPS (Tyrosine Kinase Inhibitor Optimization and Selectivity) study. Blood. 2008;112:335.

48. Conneally E, Swords RT, Giles FJ, et al. Nilotinib $300 \mathrm{mg}$ twice daily as first line treatment of $\mathrm{Ph}$-positive chronic myeloid leukemia in chronic phase: Updated results of the ICORG 0802 phase 2 study with analysis of the GeneXpert system versus IS BCR-ABL RQ PCR. Blood. 2010; 116:3427.

49. Sokal JE, Cox EB, Baccarani M, et al. Prognostic discrimination in "good-risk" chronic granulocytic leukemia. Blood. 1984;63: 789-799.

50. Hughes TP, Hochhaus A, Saglio G, et al. ENESTnd update: Continued superiority of nilotinib versus imatinib in patients with newly diagnosed chronic myeloid leukemia in chronic phase (CML-CP). Blood. 2010; 110:207. 
51. Kantarjian H, Shah NP, Hochhaus A, et al. Dasatinib versus imatinib in newly diagnosed chronic-phase chronic myeloid leukemia. $N$ Engl J Med. 2010;362:2260-2270.

52. Shah N, Kantarjian H, Hochhaus A, et al. Dasatinib versus imatinib in patients with newly diagnosed chronic myeloid leukemia in chronic phase (CML-CP) in the DASISION trial: 18 month follow-up. Blood. 2010;116:206.

53. Gambacorti-Passerini C, Kim DW, Kantarjian H, et al. An ongoing phase 3 study of bosutinib (SKI-606) versus imatinib in patients with newly diagnosed chronic phase chronic myeloid leukemia. Blood. 2010; 116:208.

54. Noens L, van Lierde MA, De Bock R, et al. Prevalence, determinants, and outcomes of nonadherence to imatinib therapy in patients with chronic myeloid leukemia: The ADAGIO study. Blood. 2009;113: 5401-5411.

55. Darkow T, Henk HJ, Thomas SK, et al. Treatment interruptions and non-adherence with imatinib and associated healthcare costs: A retrospective analysis among managed care patients with chronic myelogenous leukaemia. Pharmacoeconomics. 2007;25:481-496.

56. Marin D, Bazeos A, Mahon FX, et al. Adherence is the critical factor for achieving molecular responses in patients with chronic myeloid leukemia who achieve complete cytogenetic responses on imatinib. J Clin Oncol. 2010;28:2381-2388.

57. Deremer DL, Ustun C, Natarajan K. Nilotinib: A second-generation tyrosine kinase inhibitor for the treatment of chronic myelogenous leukemia. Clin Ther. 2008;30:1956-1975.

58. Apperley JF. Part I: Mechanisms of resistance to imatinib in chronic myeloid leukaemia. Lancet Oncol. 2007;8:1018-1029.

59. Press RD, Willis SG, Laudadio J, et al. Determining the rise in BCRABL RNA that optimally predicts a kinase domain mutation in patients with chronic myeloid leukemia on imatinib. Blood. 2009;114: 2598-2605.

60. Soverini S, Colarossi S, Gnani A, et al. Contribution of ABL kinase domain mutations to imatinib resistance in different subsets of Philadelphia-positive patients: By the GIMEMA Working Party on Chronic Myeloid Leukemia. Clin Cancer Res. 2006;12:7374-7379.

61. Shah NP, Nicoll JM, Nagar B, et al. Multiple BCR-ABL kinase domain mutations confer polyclonal resistance to the tyrosine kinase inhibitor imatinib (STI571) in chronic phase and blast crisis chronic myeloid leukemia. Cancer Cell. 2002;2:117-125.

62. Deininger M, Buchdunger E, Druker BJ. The development of imatinib as a therapeutic agent for chronic myeloid leukemia. Blood. 2005;105: 2640-2653.

63. Jabbour E, Branford S, Saglio G, et al. Practical advice for determining the role of BCR-ABL mutations in guiding tyrosine kinase inhibitor therapy in patients with chronic myeloid leukemia. Cancer. November 29, 2010. [Epub ahead of print].

64. Weisberg E, Manley P, Mestan J, et al. AMN107 (nilotinib): A novel and selective inhibitor of BCR-ABL. Br J Cancer. 2006;94:1765-1769.

65. Redaelli S, Piazza R, Rostagno R, et al. Activity of bosutinib, dasatinib, and nilotinib against 18 imatinib-resistant BCR/ABL mutants. J Clin Oncol. 2009;27:469-471.

66. Hughes T, Saglio G, Branford S, et al. Impact of baseline BCR-ABL mutations on response to nilotinib in patients with chronic myeloid leukemia in chronic phase. J Clin Oncol. 2009;27:4204-4210.

67. Bradeen HA, Eide CA, O'Hare T, et al. Comparison of imatinib mesylate, dasatinib (BMS-354825), and nilotinib (AMN107) in an N-ethyl-N-nitrosourea (ENU)-based mutagenesis screen: High efficacy of drug combinations. Blood. 2006;108:2332-2338

68. Ray A, Cowan-Jacob SW, Manley PW, et al. Identification of BCR-ABL point mutations conferring resistance to the Abl kinase inhibitor AMN107 (nilotinib) by a random mutagenesis study. Blood. 2007;109:5011-5015.

69. Kantarjian HM, Jabbour E, Giles F, et al. Prognostic factors for progression free survival in patients with imatinib resistnat or intolerant chronic myeloid leukemia in chronic phase (CML-CP) treated with nilotinib based on 24 month data. Blood. 2009;114:3298.
70. O'Hare T, Shakespeare WC, Zhu X, et al. AP24534, a pan-BCR-ABL inhibitor for chronic myeloid leukemia, potently inhibits the T315I mutant and overcomes mutation-based resistance. Cancer Cell. 2009; 16:401-412.

71. Cortes-Franco J, Khoury HJ, Nicolini FE, et al. Safety and efficacy of subcutaneous-administered omacetaxine mepesuccinate in imatinibresistant chronic myeloid leukemia (CML) patients who harbor the bcr- abl T315I mutation - results of an ongoing multicenter Phase 2/3 study. Blood. 2009;114:644.

72. Branford S, Melo JV, Hughes TP. Selecting optimal second-line tyrosine kinase inhibitor therapy for chronic myeloid leukemia patients after imatinib failure: Does the BCR-ABL mutation status really matter? Blood. 2009;114:5426-5435.

73. Von Bubnoff N, Manley PW, Mestan J, et al. Bcr-Abl resistance screening predicts a limited spectrum of point mutations to be associated with clinical resistance to the Abl kinase inhibitor nilotinib (AMN107). Blood. 2006;108:1328-1333.

74. Cortes J, Jabbour E, Kantarjian H, et al. Dynamics of BCR-ABL kinase domain mutations in chronic myeloid leukemia after sequential treatment with multiple tyrosine kinase inhibitors. Blood. 2007;110: 4005-4011.

75. Jabbour E, Kantarjian H, Jones D, et al. Frequency and clinical significance of BCR-ABL mutations in patients with chronic myeloid leukemia treated with imatinib mesylate. Leukemia. 2006;20:1767-1773.

76. O'Hare T, Eide CA, Deininger MW. Bcr-Abl kinase domain mutations, drug resistance, and the road to a cure for chronic myeloid leukemia. Blood. 2007;110:2242-2249.

77. Breccia M, Cannella L, Nanni M, et al. Nilotinib can override dasatinib resistance in chronic myeloid leukemia patients with secondary resistance to imatinib first-line therapy. Acta Haematol. 2007;118: $162-164$.

78. Soverini S, Colarossi S, Gnani A, et al. Resistance to dasatinib in Philadelphia-positive leukemia patients and the presence or the selection of mutations at residues 315 and 317 in the BCR-ABL kinase domain. Haematologica. 2007;92:401-404.

79. Hochhaus A, Saglio G, Larson R, et al. Nilotinib lowers the incidence of BCR-ABL mutations and improves the molecular response kinetics compared with imatinib in patients (Pts) with newly diagnosed chronic myeloid leukemia (CML). Blood. 2010;116:3431.

80. Eghtedar A, Kantarjian H, Jabbour E, et al. Outcome after failure to second generation tyrosine kinase inhibitors (TKI) treatment as frontline therapy for patients with chronic myeloid leukemia (CML) in chronic phase (CP). Blood. 2010:116.

81. Package insert. Tasigna (nilotinib). East Hanover, NJ: Novartis Pharmaceuticals; 2010.

82. Mauro MJ, Deininger MW. Management of drug toxicities in chronic myeloid leukaemia. Best Pract Res Clin Haematol. 2009;22:409-429.

83. Quintas-Cardama A, Kantarjian H, O'Brien S, et al. Pleural effusion in patients with chronic myelogenous leukemia treated with dasatinib after imatinib failure. J Clin Oncol. 2007;25:3908-3914.

84. Cohen MH, Williams G, Johnson JR, et al. Approval summary for imatinib mesylate capsules in the treatment of chronic myelogenous leukemia. Clin Cancer Res. 2002;8:935-942.

85. Quintas-Cardama A, Kantarjian HM, Munden R, et al. Pleural effusion in patient (pts) with chronic myelogenous leukemia (CML) treated with dasatinib after imatinib failure. Blood. 2006;108:Abstr 2164.

86. Shah NP, Kantarjian HM, Kim DW, et al. Intermittent target inhibition with dasatinib $100 \mathrm{mg}$ once daily preserves efficacy and improves tolerability in imatinib-resistant and -intolerant chronic-phase chronic myeloid leukemia. J Clin Oncol. 2008;26:3204-3212.

87. Lombardo LJ, Lee FY, Chen P, et al. Discovery of N-(2-chloro6-methyl- phenyl)-2-(6-(4-(2-hydroxyethyl)- piperazin-1-yl)-2methylpyrimidin-4- ylamino)thiazole-5-carboxamide (BMS-354825), a dual Src/Abl kinase inhibitor with potent antitumor activity in preclinical assays. J Med Chem. 2004;47:6658-6661.

88. Pietras K, Sjoblom T, Rubin K, et al. PDGF receptors as cancer drug targets. Cancer Cell. 2003;3:439-443. 
89. Bergeron A, Rea D, Levy V, et al. Lung abnormalities after dasatinib treatment for chronic myeloid leukemia: A case series. Am J Respir Crit Care Med. 2007;176:814-818.

90. De Lavallade H, Punnialingam S, Milojkovic D, et al. Pleural effusions in patients with chronic myeloid leukaemia treated with dasatinib may have an immune-mediated pathogenesis. Br J Haematol. 2008;141: 745-747.

91. Lipton JH, Sriharsha I, Bogomilsky S, et al. Pleural effusions in patients treated with dasatinib: Results from two institutions, risk factors, and management. J Clin Oncol. 2007;25:17503.

92. Cortes J, Rousselot P, Kim DW, et al. Dasatinib induces complete hematologic and cytogenetic responses in patients with imatinibresistant or -intolerant chronic myeloid leukemia in blast crisis. Blood. 2007;109:3207-3213.

93. Kantarjian HM, Giles F, Hochhaus A, et al. Nilotinib in patients with imatinib-resistant or -intolerant chronic myelogenous leukemia in chronic phase (CML-CP): Updated Phase II results. J Clin Oncol. 2008; 126:7010

94. Santos FP, Kantarjian H, Fava C, et al. Clinical impact of dose reductions and interruptions of second-generation tyrosine kinase inhibitors in patients with chronic myeloid leukaemia. Br J Haematol. 2010;150: 303-312.

95. Bacik J, Mazumdar M, Murphy BA, et al. The functional assessment of cancer therapy-BRM (FACT-BRM): A new tool for the assessment of quality of life in patients treated with biologic response modifiers. Qual Life Res. 2004;13:137-154.

96. Hahn EA, Glendenning GA, Sorensen MV, et al. Quality of life in patients with newly diagnosed chronic phase chronic myeloid leukemia on imatinib versus interferon alfa plus low-dose cytarabine: Results from the IRIS Study. J Clin Oncol. 2003;21:2138-2146.

97. Pinilla-Ibarz J, Cortes J, Mauro MJ. Intolerance to tyrosine kinase inhibitors in chronic myeloid leukemia: Definitions and clinical implications. Cancer October 4, 2010. [Epub ahead of print].

98. Williams LA, Ault P, Wang XS, et al. The symptom burden of chronic myelogenous leukemia (CML). Blood. 2008;112:2408.
99. Druker BJ, Tamura S, Buchdunger E, et al. Effects of a selective inhibitor of the Abl tyrosine kinase on the growth of Bcr-Abl positive cells. Nat Med. 1996;2:561-566.

100. Kantarjian H, Talpaz M, O’Brien S, et al. High-dose imatinib mesylate therapy in newly diagnosed Philadelphia chromosome-positive chronic phase chronic myeloid leukemia. Blood. 2004;103:2873-2878.

101. Kantarjian H, O’Brien S, Shan J, et al. Cytogenetic and molecular responses and outcome in chronic myelogenous leukemia: Need for new response definitions? Cancer. 2008;112:837-845.

102. De Lavallade H, Apperley JF, Khorashad JS, et al. Imatinib for newly diagnosed patients with chronic myeloid leukemia: Incidence of sustained responses in an intention-to-treat analysis. J Clin Oncol. 2008;26:3358-3363.

103. Cortes J, Talpaz M, Bixby D, et al. A phase 1 trial of oral ponatinib (AP24534) in patients with refractory chronic myelogenous leukemia (CML) and other hematologic malignancies: Emerging safety and clinical response findings. Blood. 2010;116:210.

104. Cortes J, Paquette R, Talpaz M, et al. Preliminary clinical activity in a phase I trial of the BCR-ABL/IGF-1R/aurora kinase inhibitor XL228 in patients with $\mathrm{Ph}+$ leukemias with either failure to multiple TKI therapies or with T315I mutation. Blood. 2008:Abstr 3232.

105. Borthakur G, Kantarjian H, Daley G, et al. Pilot study of lonafarnib, a farnesyl transferase inhibitor, in patients with chronic myeloid leukemia in the chronic or accelerated phase that is resistant or refractory to imatinib therapy. Cancer. 2006;106:346-352.

106. Fiskus W, Pranpat M, Bali P, et al. Combined effects of novel tyrosine kinase inhibitor AMN107 and histone deacetylase inhibitor LBH589 against Bcr-Abl-expressing human leukemia cells. Blood. 2006;108: 645-652.

107. Fiskus W, Wang Y, Joshi R, et al. Cotreatment with vorinostat enhances activity of MK-0457 (VX-680) against acute and chronic myelogenous leukemia cells. Clin Cancer Res. 2008;14:6106-6115.
Cancer Management and Research

\section{Publish your work in this journal}

Cancer Management and Research is an international, peer-reviewed open access journal focusing on cancer research and the optimal use of preventative and integrated treatment interventions to achieve improved outcomes, enhanced survival and quality of life for the cancer patient. The journal welcomes original research, clinical \& epidemiological

\section{Dovepress}

studies, reviews \& evaluations, guidelines, expert opinion \& commentary, case reports \& extended reports. The manuscript management system is completely online and includes a very quick and fair peerreview system, which is all easy to use. Visit http://www.dovepress.com/ testimonials.php to read real quotes from published authors. 